ROCZNIKI HUMANISTYCZNE

Tom LXIX, zeszyt $12-2021$

DOI: https://doi.org/10.18290/rh216912-2

MACIEJ JOCHYMCZYK

\title{
NIEZNANE TRIA SMYCZKOWE AMANDA IVANSCHIZA OSPPE (1727-1758)
}

Tytuł niniejszego artykułu w szerszym rozumieniu odnosi się do wszystkich triów smyczkowych paulińskiego kompozytora Amanda Ivanschiza (1727-1758), które przez blisko dwa stulecia spoczywały w zakamarkach archiwów, a ich znaczenie umykało uwadze współczesnych badaczy. W węższym zakresie dotyczy on natomiast nieznanych triów tego autora, które zachowały się w zbiorach klasztoru benedyktynów w Melk (Austria) i nie były dotychczas wzmiankowane w literaturze.

Trio smyczkowe to gatunek muzyki instrumentalnej niezwykle popularny w II połowie XVIII wieku, jednak obecnie w dużej mierze zapomniany i pozostający w cieniu kwartetu smyczkowego (Unverricht; Brook, „Haydn's String Trios" 61-77). O znaczeniu tego pierwszego świadczy chociażby fakt, że w latach 1750-1780 powstawało znacznie więcej triów smyczkowych niż kwartetów, na co wskazują m.in. katalogi tematyczne publikowane wówczas przez firmę Breitkopf (Brook, „Haydn's String Trios” 62, 74; Brook, The Breitkopf Thematic Catalogue).

Jednym z kompozytorów, którzy tworzyli podwaliny tego gatunku, był Amandus Ivanschiz. Jego rola nie została jednak dostrzeżona przez wcześniejszych badaczy ze względu na nieznajomość biografii autora i wynikające z tego błędne (znacznie późniejsze) datowanie zachowanej twórczości. Ivanschiz przyszedł na świat tuż przed świętami Bożego Narodzenia 1727 roku (Jochymczyk 21-48).

Dr MACIEJ JochYMCZYK - Uniwersytet Jagielloński, Wydział Historyczny, Instytut Muzykologii; adres do korespondencji: ul. Westerplatte 10,31-033 Kraków; e-mail: maciej.jochymczyk@uj.edu.pl; ORCID: https://orcid.org/0000-0003-0967-9681.

Dr. MACIEJ JochymczYK, Jagiellonian University, Faculty of History, Institute of Musicology; address for correspondence: ul. Westerplatte 10, 31-033 Kraków, Poland; e-mail: maciej.jochymczyk@uj.edu.pl; ORCID: https://orcid.org/0000-0003-0967-9681. 
Data dzienna narodzin nie jest znana, lecz wiadomo, że został ochrzczony 24 grudnia w austriackim Wiener Neustadt, otrzymując imiona Matthias Leopold. Jego ojciec pochodził z wioski Baumgarten zamieszkałej przez mniejszość chorwacką. Po odbyciu nowicjatu, młody Matthias Leopold złożył śluby zakonne (25 grudnia 1743 roku) i przyjął imię Amandus. Przygotowując się do prezbiteratu, studiował w Maria Trost (koło Grazu) i Wiener Neustadt, a 15 listopada 1750 roku otrzymał święcenia kapłańskie. W latach 1751-1754 kompozytor przebywał w Rzymie, pełniąc funkcję pomocnika (socius) prokuratora generalnego zakonu. Począwszy od 1755 roku ponownie odnotowujemy obecność o. Amanda w klasztorze Maria Trost. Tam też zmarł w 1758 roku, w wieku zaledwie 31 lat (Jochymczyk 44-46).

XX-wieczni badacze, sugerując się datowaniem zachowanych kopii utworów, a także ich wczesnoklasyczną stylistyką, sądzili, iż kres aktywności kompozytora przypadł na lata 60., 70., a nawet 90. XVIII wieku (m.in. Andreis 72; Flotzinger i Gruber 97; Vidaković 722; Županović 141-152; zob. Jochymczyk 12-20). Dopiero stosunkowo niedawne odkrycie daty śmierci Ivanschiza (Jochymczyk 44-46) pozwoliło poprawnie umiejscowić w czasie jego twórczość, stawiając ją w nowym świetle i niejednokrotnie zmieniając naszą wiedzę o zachodzących wówczas przemianach, zwłaszcza na gruncie gatunków muzyki instrumentalnej - symfonii i tria smyczkowego.

W katalogu tematycznym dzieł Ivanschiza (Jochymczyk 329-474) uwzględniono dotychczas 12 triów smyczkowych, których autorstwo nie budzi wątpliwości (a także trzy zaginione i sześć kolejnych, które prawdopodobnie mylnie przypisywano temu kompozytorowi). Wszystkie utwory o pewnym autorstwie łączą wyraźne podobieństwa, zwłaszcza dotyczące obsady i formy muzycznej. $\mathrm{Z}$ jednym wyjątkiem (Trio in F T.F.1) ${ }^{1}$ są to kompozycje trzyczęściowe, zbudowane według schematu: (1) część wolna - (2) menuet z triem - (3) część szybka. Wszystkie utrzymane są $\mathrm{w}$ fakturze trzygłosowej i przeznaczone na trzy solowe instrumenty: najwyższą partię realizują skrzypce, głos środkowy powierzany jest skrzypcom lub altówce, zaś partia najniższa wymaga nisko brzmiącego instrumentu smyczkowego. Na okładkach rękopisów najczęściej figurują tytuły Trio, A tre, Divertimento lub Sonata, rzadziej Simfonia (czy Sinfonia), a jednorazowo Sonatina. Wszystkie przytoczone terminy są jednak stosowane wymiennie, bez związku z formą bądź stylistyką kompozycji. Z reguły ten sam utwór w rękopisach różnej proweniencji jest nazywany inaczej. Dla przykładu Trio in $C$ (T.C.1) w zachowanych przekazach tytułowane jest Trio, Divertimento, Sonata lub Sonatina (Jochymczyk 457). Na podstawie

\footnotetext{
${ }^{1}$ Oznaczenia utworów wg katalogu tematycznego dzieł Ivanschiza (Jochymczyk 329-474).
} 
przeanalizowanego korpusu dzieł Ivanschiza możemy stwierdzić, że zastosowanie takiego czy innego określenia jest związane głównie z lokalną tradycją terminologiczną, na przykład na okładkach wszystkich triów przechowywanych $\mathrm{w}$ archiwum wiedeńskiego Gesellschaft der Musikfreunde (spisanych przez jednego skryptora) figuruje termin Simfonia. Taka swoboda w zakresie nazewnictwa nowych gatunków muzyki instrumentalnej w XVIII wieku jest zjawiskiem dostrzeganym przez współczesnych badaczy (Webster 213).

Nieliczne datowane przekazy triów Ivanschiza, a także katalogi oficyn Breitkopfa i Ringmachera, oferujących rękopiśmienne kopie na zamówienie, wskazują, że utwory te były wykonywane i rozpowszechniane również po śmierci autora, szczególnie w latach 60. i 70. XVIII wieku, a pojedyncze dzieła znajdowały się w użyciu prawdopodobnie nawet w I połowie XIX wieku, później jednak popadły w zapomnienie. Ponowne odkrycie kameralnej muzyki instrumentalnej Ivanschiza w latach 80. XX wieku zawdzięczamy głównie wydaniom Danilo Pokorna i Paula M. Douglasa. Niestety edycje aż sześciu z dziewięciu zamieszczonych w nich kompozycji oparto na źródłach pochodzących ze zbiorów margrabiów badeńskich, przechowywanych w Badische Landesbibliothek w Karlsruhe. Wybór ten okazał się szczególnie niefortunny, ponieważ w rękopisach badeńskich utwory Ivanschiza zostały poddane istotnym modyfikacjom - przede wszystkim w większości źródeł partię skrzypiec powierzono fletowi traverso, dostosowując ją do możliwości i skali tego instrumentu². W trzech przypadkach pod nazwiskiem Ivanschiza opublikowane zostały utwory Franza Asplmayra - T(dub).G.1, T(dub).D.1 - mylnie przypisane paulińskiemu kompozytorowi w zbiorze badeńskim ${ }^{3}$. Pewnych modyfikacji obsady dokonali wreszcie redaktorzy zeszytów - pomimo tego, że z zachowanych przekazów wynika, iż najniższy głos w triach wykonywany był zwykle na wiolonczeli i w żadnym ze źródeł nie jest cyfrowany, we wszystkich trzech wydaniach utwory wzbogacono o zrealizowaną partię basso continuo (w zeszytach pod redakcją Danilo Pokorna nazwaną po prostu „cembalo”), nie oznaczając wyraźnie, że pochodzi ona od wydawcy. W ten sposób nowatorstwo Ivanschiza i jego wkład w wykształcenie klasycznego tria smyczkowego zostały skutecznie zakamuflowane przez wydawców.

W pewnym uproszczeniu można przyjąć, że główny kierunek przemian tego gatunku w XVIII wieku wiązał się z odejściem od obsady i faktury typowej dla barokowej sonaty triowej (a due lub a tre - na dwa instrumenty sopranowe,

\footnotetext{
${ }^{2}$ Autorem aranżacji był najprawdopodobniej nadworny flecista, Johann Reusch (Jochymczyk 118-119)

${ }^{3} \mathrm{Na}$ niską wiarygodność zbioru badeńskiego, a nawet mylne przypisanie Ivanschizowi tria Asplmayra opracowanego na flet wskazywał już Hubert Unverricht (71).
} 
ewentualnie trzeci melodyczny instrument basowy i basso continuo) ku utworom przeznaczonym na skrzypce, altówkę i wiolonczelę ${ }^{4}$. Wedle opinii Warrena Kirkendale'a (93) pierwszy po taką obsadę miał sięgnąć Luigi Boccherini w triach op. 14 z 1772 roku. Z kolei autorzy hasła „String trio” w czołowej anglojęzycznej encyklopedii muzycznej The New Grove Dictionary of Music and Musicians (Tilmouth i Smallman 596-597) sugerują, iż wcześniej to Józef Haydn mógł być kompozytorem, który jako pierwszy do tego zestawu wprowadził altówkę, zaś eliminacja basso continuo nastąpiła stopniowo w latach 70. i 80. XVIII wieku. Poglądy te należy obecnie zweryfikować, biorąc pod uwagę fakt, że w żadnej z kilkudziesięciu kopii triów Ivanschiza najniższa partia nie jest cyfrowana. Określana jest - podobnie jak w triach Haydna (Brook 75) - najczęściej terminem basso lub violoncello i przeznaczona do wykonania na melodycznym instrumencie smyczkowym ${ }^{5}$. W tym kontekście znacznie trafniejsze wydają się obserwacje Jamesa Webstera (243-244), który wskazuje na liczne dowody, iż partia continuo w austriackiej muzyce kameralnej w dużej mierze wyszła z użycia już przed 1750 rokiem. Ponadto większość swoich triów Ivanschiz skomponował na skrzypce, altówkę i wiolonczelę, a więc skład charakterystyczny dla dojrzałego tria klasycznego. Przy tym rola altówki w jego utworach (inaczej niż rola drugich skrzypiec) nie jest ograniczana do tworzenia wypełnienia harmonicznego - kompozytor traktuje ją równorzędnie ze skrzypcami, a obydwa górne instrumenty często dialogują (nawet z uwzględnieniem krzyżowania głosów). Wczesnoklasyczna w triach Ivanschiza jest nie tylko obsada. Nowoczesne cechy języka muzycznego widoczne są również na gruncie innych elementów dzieła muzycznego. Kompozytor wykorzystuje głównie fakturę homofoniczną, a melodyka przybiera wyraźną budowę okresową (niekoniecznie symetryczną), wspieraną regularnymi kadencjami. Tempo zmian harmonicznych jest powolne, a modulacje prowadzą jedynie do blisko spokrewnionych tonacji. W zakresie architektoniki zwraca uwagę obecność struktur, które można uznać za prototypy późniejszej formy sonatowej, z bardzo ograniczonym odcinkiem przetworzeniowym (Jochymczyk 247-269). Omówione tu cechy triów Ivanschiza są warte uwagi tym

\footnotetext{
${ }^{4}$ Laurenz Lütteken postuluje wręcz ograniczenie stosowania terminu „trio smyczkowe” wyłącznie do utworów na taką właśnie obsadę. Taki pogląd nie jest jednak podzielany przez innych autorów i nie wydaje się dostatecznie uzasadniony. Tria na dwoje skrzypiec i wiolonczelę zwykle nie różniły się stylistycznie od utworów przeznaczonych na skrzypce, altówkę i wiolonczelę, i komponowane były nadal nawet w XIX wieku.

${ }^{5}$ Jedynym znanym obecnie wyjątkiem od tej zasady jest nieautorska kopia Tria T.C.1 z klasztoru cystersów w Bildhausen w Niemczech (zdeponowana w Archiwum diecezjalnym w Würzburgu, sygn. KBD/KES K7 Ms091) zawierająca na karcie tytułowej następującą inskrypcję: „Sonatina Tono Del C | â 3 Stromenti | Violino Solo | Viola Solo | Con | Basso Continuo".
} 
bardziej, że utwory te powstały prawdopodobnie wcześniej niż tria młodszego o pięć lat Józefa Haydna. Wobec wszechobecnych problemów z datowaniem zachowanych kompozycji, muzyka o. Amanda okazuje się szczególnie wartościowym materiałem badawczym, ponieważ nieprzekraczalny terminus ante quem wyznacza jego przedwczesna śmierć w 1758 roku.

Tabela 1. Tria Amanda Ivanschiza w zbiorach klasztoru benedyktynów w Melk (A-M)

\begin{tabular}{|c|c|c|}
\hline Sygnatura & Treść karty tytułowej & $\begin{array}{l}\text { Nr w katalogu } \\
\text { dzieł Ivanschiza }\end{array}$ \\
\hline VI 880 & $\begin{array}{l}\text { Divertimento Ex } D|a| \text { Violino Solo } \mid \text { Viola Solo } \mid \text { et } \mid \text { Basso } \mid \\
\text { Auctore Ivanschitz }\end{array}$ & T.E.1 \\
\hline V 81 & $\begin{array}{l}\text { Divertimento Ex F | a } 3 \text { Voc: } \mid \text { Violino Primo |Viola Concer: } \mid \\
\text { Con | Basso } \mid \text { Auth Del Sig'e Heyden [innym charakterem } \\
\text { pisma wykreślono nazwisko i dopisano: Ivanschitz] }\end{array}$ & T.F.2 \\
\hline V 1432 & $\begin{array}{l}\text { Simfonia ex } F \mid \text { Violino } I^{\text {mo }} \mid \text { Violino } I^{d o}|e| \text { Basso } \mid \text { Del Sig }{ }^{\text {re }} \\
\text { Amando Ivanschiz }\end{array}$ & T.F.3 \\
\hline V 1429 & $\begin{array}{l}\text { Sinfonia Divertimente } \mid \text { Violino Solo } \mid \text { Viola } \mid \text { e } \mid \text { Basso } \mid \text { Del } \\
\text { Sige Ivanschiz }\end{array}$ & T.B.1 \\
\hline V 1430 & $\begin{array}{l}\text { Sinfonia ex } D \mid \text { Violino Imo } \mid \text { Violino II }{ }^{\text {do }}|e| \text { Basso } \mid \text { del Sigre } \\
\text { Amando Ivanschiz }\end{array}$ & [T.D.1] \\
\hline V 1431 & $\begin{array}{l}\text { Simfonia ex Eb } \mid \text { Violino I } \mid \text { Violino II } \mid \text { e } \mid \text { Basso } \mid \text { Del Sigre } \\
\text { Amando Ivanschiz }\end{array}$ & [T.Es.2] \\
\hline
\end{tabular}

Dzięki najnowszym ustaleniom w ostatnim czasie grupa triów smyczkowych Ivanschiza poszerzyła się o nieuwzględnione wcześniej w literaturze pozycje ze zbiorów klasztoru benedyktynów w Melk w Austrii ${ }^{6}$. Znajduje się tam sześć rękopisów zawierających cztery tria zachowane również w innych kolekcjach, a także dwa unikatowe przekazy dotychczas nieznanych kompozycji tego gatunku. Do pierwszej grupy należą Divertimento Ex F (T.F.2), Divertimento Ex D (T.E.1), Simfonia ex F (T.F.3) oraz Sinfonia Divertimente (T.B.1), zaś do drugiej Sinfonia ex D i Simfonia ex Eb (w katalogu tematycznym dzieł Ivanschiza dwa ostatnie utwory otrzymają oznaczenia odpowiednio T.D.1 i T.Es.2; omawiane rękopisy nie zostały dotąd uwzględnione w bazie RISM, dlatego odpisy kart tytułowych przedstawiono w tabeli 1, a incipity

\footnotetext{
${ }^{6} \mathrm{Za}$ cenne informacje i pomoc $\mathrm{w}$ dostępie do źródeł uprzejmie dziękuję kustoszowi zbiorów muzycznych z Melk, dr. Johannesowi Prominczelowi.
} 
muzyczne dwóch przekazów unikatowych w przykładzie 1). Trio T.E.1 zostało w przekazie z Melk przetransponowane o sekunde niżej - z E-dur do D-dur. W takiej postaci zapisano je również $\mathrm{w}$ źródle pochodzącym $\mathrm{z}$ innego klasztoru benedyktynów w Rajhradzie na Morawach, co może być świadectwem wymiany repertuaru pomiędzy tymi ośrodkami.

a) Sinfonia ex D [T.D.1]:

I. Andantino - Allegro assai - Andantino - Allegro assai

Vn I

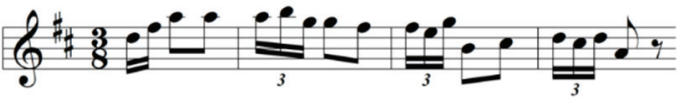

II. Menuet

Vn I

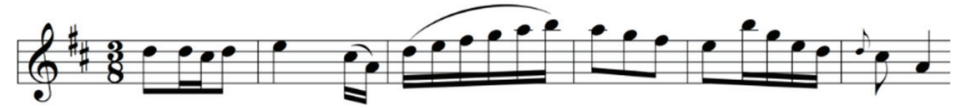

III. Finale [Allegro]

$\mathrm{Vn}$

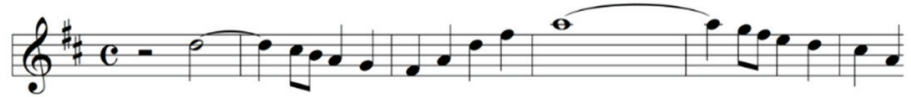

b) Simfonia ex Eb [T.Es.2]:

I. Andantino

Vn I

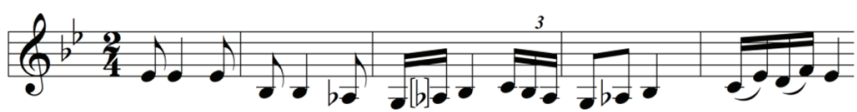

II. Menuet

Vn I

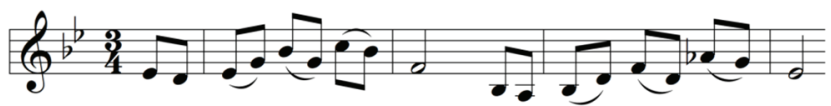

III. Allegro assai

Vn I

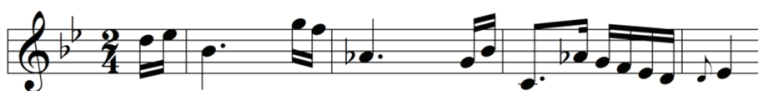

Przykład 1. Incipity unikatowych przekazów triów smyczkowych Amanda Ivanschiza zachowanych w klasztorze benedyktynów w Melk (A-M)

Wszystkie omawiane rękopisy są kompletne, a autorstwo utworów przypisano Ivanschizowi (w jednym przypadku skreślając zanotowane wcześniej nazwisko „Heyden”). Dwie nieznane dotychczas kompozycje posiadają liczne cechy typowe 
dla triów o. Amanda. Zbudowane są z trzech części w układzie: (1) część wolna, (2) menuet z triem, (3) część szybka, jak zwykle utrzymanych w tej samej tonacji (z wyjątkiem tria menueta). Obydwa przeznaczone są na dwoje skrzypiec i wiolonczelę (basso), a sposób prowadzenia głosów i ich wzajemne relacje bardzo przypominają pozostałe tria paulińskiego kompozytora. W ustępach skrajnych Simfonii ex Eb T.Es.2 (Andantino i Allegro assai) wykorzystana została prosta forma sonatowa z krótkim odcinkiem ,przetworzeniowym”. Menueta zapisano w metrum 3/4, a wewnętrzna część tańca skomponowana jest w paralelnej tonacji molowej (c-moll). Sinfonia ex D T.D.1 posiada bardziej niekonwencjonalną konstrukcję. W części pierwszej, zbudowanej według schematu $A B:\left\|: A^{\prime} B^{\prime}:\right\|$, zestawiane są dwa bloki tematyczne skontrastowane pod względem tempa i metrum - materiał A utrzymany jest w tempie Andantino i metrum 3/8, a materiał B w tempie Allegro assai i metrum 2/4 (podobne rozwiązanie zastosował Ivanschiz w finale Symfonii in $G$ S.G.1). W menuecie, tym razem skomponowanym w metrum 3/8, zwraca uwagę tonacja części środkowej (B-dur), która jest dość odległa od tonacji głównej cyklu (identyczną relację znajdziemy również w menuecie z Symfonii in D S.D.5). Jak zwykle u Ivanschiza, charakter tej części przywodzi na myśl raczej muzykę ludową niż taniec dworski. Z kolei cechą szczególną finału jest zastosowanie faktury polifonicznej, po którą o. Amandus sięgał stosunkowo rzadko w utworach instrumentalnych. Biorąc pod uwagę wszystkie cechy języka muzycznego, atrybucja dwóch nowo odnalezionych utworów nie budzi wątpliwości i możemy je uznać za dzieła Ivanschiza.

Okładki czterech triów z Melk o sygnaturach V 1429-1432 łączą wyraźne podobieństwa. Wszystkie zostały zanotowane tą samą ręką i noszą tytuł Sinfonia (lub Simfonia) bardzo rzadko stosowany w odniesieniu do utworów tego gatunku. Rękopisy te zostały włączone do kolekcji klasztoru w Melk stosunkowo późno, w 1838 roku (informują o tym stosowne adnotacje na okładkach), jednak powstały z pewnością wcześniej. Centralnie, na górze każdej z kart tytułowych widoczne są wykreślone dawne sygnatury zaczynające się od charakterystycznej sekwencji znaków „XIII 1325/gg” (przykł. 2). Sygnatury tego rodzaju posiadają niektóre rękopisy muzyczne z archiwum wiedeńskiego Gesellschaft der Musikfreunde. Co więcej - jak już wspomniano - w zbiorze tym znajdują się inne tria Ivanschiza również określone mianem Simfonia (sygn. olim: XIII 1325/gg, XIII 8549/gg, XIII 8550/gg). Porównanie rękopisów pozwala stwierdzić bez cienia wątpliwości, że zostały one zanotowane przez tego samego skryptora, co rękopisy z Melk. Niewątpliwie wszystkie należały początkowo do tej samej kolekcji. Archiwum Gesellschaft der Musikfreunde pozyskało je prawdopodobnie około 1820 roku. Niestety pierwotna proweniencja 
rękopisów nie jest znana. Nie wiadomo również, w jakich okolicznościach dziesięć lat później cztery manuskrypty zostały przeniesione z Wiednia do Melk.

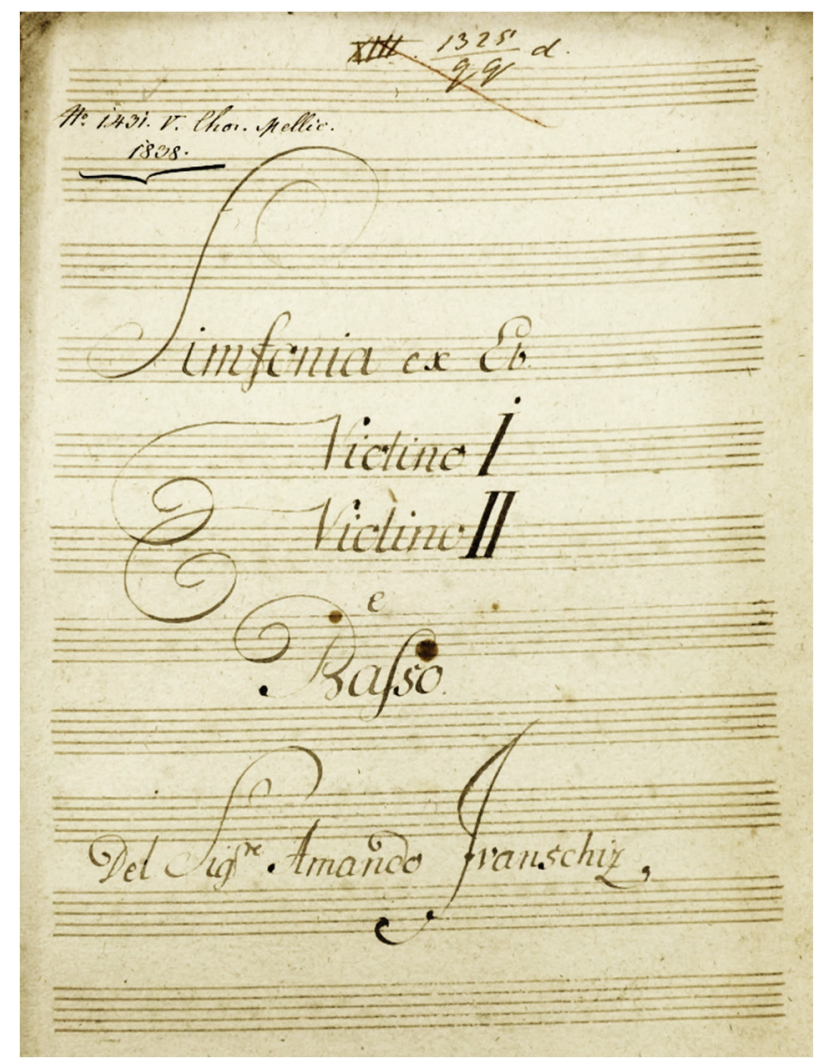

Przykład 2. Klasztor benedyktynów w Melk (A-M), sygn. V 1431,

Simfonia ex Eb, karta tytułowa

Obecne miejsce przechowywania omawianych utworów skłania również do refleksji nad miejscem triów smyczkowych w ówczesnej praktyce wykonawczej. Chociaż gatunek ten kojarzy się dziś raczej z kontekstem świeckim, to zachowane źródła (a także biografia i twórczość samego Ivanschiza) dokumentują obecność kameralnej muzyki instrumentalnej w życiu muzycznym klasztorów. Jak można sądzić, znajdowała ona swoje zastosowanie szczególnie w czasie rekreacji, wypełniając zakonnikom czas wolny od innych obowiązków (co nie zawsze pozostawało w zgodzie z zarządzeniami władz zakonnych); mogła być również wykorzystywana dla uświetnienia wizyt ważnych gości czy innych wydarzeń odbywających się poza murami kościoła. W tym względzie 
utwory Ivanschiza nie były wyjątkiem. Świadectwem obecności w życiu zakonnym świeckiej muzyki instrumentalnej, z pewnością nienadającej się do użytku liturgicznego, są chociażby suity na lutnię (solo lub z towarzyszeniem innych instrumentów) zachowane m.in. w kolekcjach pochodzących z klasztorów benedyktynów w Göttweig, Kremsmünster, Rajhradzie i Seitenstetten, norbertanów w Pradze czy cystersów w śląskim Krzeszowie (Steur i Lutz).

Dodajmy, że w ostatnich dekadach muzyka Ivanschiza znalazła się w obszarze zainteresowania polskich muzykologów i wykonawców dzięki projektowi badawczemu poświęconemu zbiorom muzycznym Jasnej Góry. Wprawdzie, wedle obecnego stanu wiedzy, kompozytor nigdy nie przebywał na terenie Polski, a $\mathrm{w}$ archiwum częstochowskiego klasztoru zachowały się zaledwie dwa przypisywane mu dzieła, jednak jego twórczość doskonale wpisuje się w założenia odkrywania kultury muzycznej paulinów, zaświadczając jednocześnie o jej wysokiej randze artystycznej. Dzięki temu nagrania wielu triów Ivanschiza, w różnych wykonaniach i wariantach obsadowych, dostępne są w serii Jasnogórska Muzyka Dawna-Musica Claromontana.

\section{BIBLIOGRAFIA}

Andreis, Josip. „Razvoj muzičke umjetnosti u Hrvatskoj”. Historijski razvoj muzičke kulture u Jugoslaviji, red. Josip Andreis i in., 1962, ss. 11-280.

Brook, Barry S. „Haydn’s String Trios: a Misunderstood Genre”. Current Musicology, nr 36, 1983, ss. 61-77.

Brook, Barry S., redaktor. The Breitkopf Thematic Catalogue: The Six Parts and Sixteen Supplements 1762-1787. Dover Publications, 1966.

Douglas, Paul M., redaktor. Amandus Ivanschiz: Six sonatas a tre for flute, viola, and basso continuo, t. 1, nr. 1-3, Nova Music, 1982.

Flotzinger, Rudolf, i Gernot Gruber. „Die Epoche zwischen den Epochen”. Musikgeschichte Österreichs, t. 2: Vom Barock zur Gegenwart, red. Rudolf Flotzinger, Gernot Gruber, Verlag Styria, 1979, ss. 75-113.

Jochymczyk, Maciej. Amandus Ivanschiz - His Life and Music. With a Thematic Catalog of Works. Musica Iagellonica, 2016.

Kirkendale, Warren. Fuge und Fugato in der Kammermusik des Rokoko und der Klassik. Schneider, 1966.

Lütteken, Laurenz. „Streichtrio”. Die Musik in Geschichte und Gegenwart Online, www.mggonline.com/mgg/stable/16098. Dostęp 10.02.2021.

Pokorn, Danilo, redaktor. Amandus Ivančič: Sonate a tre. Znanstvenoraziskovalni center Slovenske akademije znanosti in umetnosti, 1983. Monumenta artis musicae Sloveniae I. Reedycja online opatrzona nowym wstępem, DOI: 10.3986/9790709004386. Dostęp 16.02.2021.

Pokorn, Danilo, redaktor. Amandus Ivančič: Simfonije za dve violini in bas. Znanstvenoraziskovalni center Slovenske akademije znanosti in umetnosti, 1984. Monumenta artis musicae Sloveniae III. Reedycja online opatrzona nowym wstępem, DOI: 10.3986/9790709004393. Dostęp 16.02.2021. 
Ringmacher, Christian Ulrich. Catalogo de' soli, duetti, trii, quadri, quintetti, partite, de' concerti e delle sinfonie per il cembalo, violino, flauto traverso ed altri stromenti che si trovano in manoscritto nella officina musica di Christiano Ulrico Ringmacher librario in Berolino. Ringmacher, 1773.

Steur, Peter i Markus Lutz. Music for Lute Instruments. A Database. mss.slweiss.de. Dostęp 15.02.2021.

Tilmouth, Michael, i Basil Smallman. „String trio”. The New Grove Dictionary of Music and Musicians, red. Stanley Sadie, wyd. 2, t. 24, Macmillan Publishers, 2001, ss. 596-597.

Unverricht, Hubert. Geschichte des Streichtrios. Schneider, 1969. Mainzer Studien zur Musikwissenschaft, t. 2.

Vidaković, Albe. „Ivančić, Amando”. Muzička enciklopedija, t. 1, Leksikografski zavod FNRJ, 1958, s. 722 .

Webster, James. „Towards a History of Viennese Chamber Music in the Early Classical Period”. Journal of the American Musicological Society, t. 27, nr 2, 1974, ss. 212-247.

Županović, Lovro. Centuries of Croatian Music. Tłum. Vladimir Ivir, t. 1, Music Information Center, 1984.

NIEZNANE TRIA SMYCZKOWE AMANDA IVANSCHIZA OSPPE (1727-1758)

Streszczenie

Trio smyczkowe to gatunek niezwykle popularny w II połowie XVIII wieku, jednak obecnie w dużej mierze zapomniany i pozostający w cieniu kwartetu smyczkowego. Jednym z kompozytorów, którzy tworzyli podwaliny tego gatunku był austriacki paulin, o. Amandus Ivanschiz (1727-1758). Jego rola nie została jednak dostrzeżona przez wcześniejszych badaczy ze względu na nieznajomość biografii autora i wynikające $\mathrm{z}$ tego błędne (znacznie późniejsze) datowanie zachowanej twórczości. Celem artykułu jest przedstawienie wkładu Ivanschiza w wykształcenie klasycznego tria smyczkowego, a także prezentacja sześciu niewzmiankowanych w literaturze źródeł ze zbiorów klasztoru benedyktynów w Melk (Austria), wśród których znajdują się dwa nieznane dotychczas utwory o. Amanda.

Słowa kluczowe: Amandus Ivanschiz; trio smyczkowe; altówka; muzyka XVIII w.

\section{UNKNOWN STRING TRIOS BY AMANDUS IVANSCHIZ OSPPE (1727-1758)}

\section{S u m m a ry}

The genre of the string trio, extremely popular in the second half of the eighteenth century, is now largely forgotten and overshadowed by the string quartet. One of the composers who created the foundations of this genre was the Austrian Pauline monk Fr. Amandus Ivanschiz (1727-1758). However, his role in this field was not noted by researchers due to a lack of knowledge about his life, resulting in a wrong (much later) dating of his works. The aim of this article is to discuss Ivanschiz's contribution to the development of the classical string trio and to present six sources from the Benedictine monastery in Melk (Austria) which contain, among others, two previously unknown trios by Fr. Amandus.

Keywords: Amandus Ivanschiz; string trio; viola; 18 th-century music. 